\title{
The Value of Judgments Regarding the Value of Animals
}

\author{
Margaret Ayotte Levvis \\ Clemson University
}

Editors' Note: Professor Levvis' paper was presented at the Central Division meeting of the Society for the Study of Ethics and Animals held in Chicago, Illinois, April, 1991.

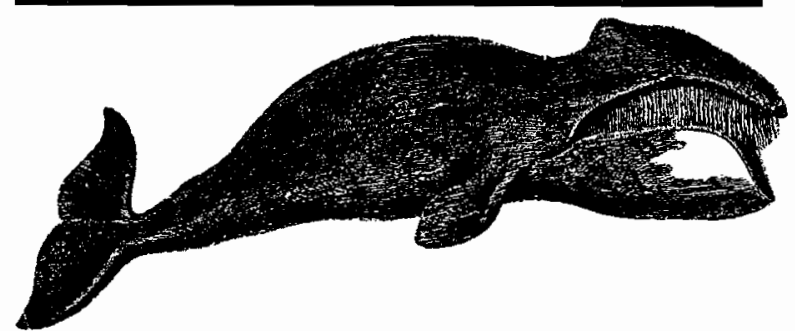

Contemporary skepticism concerning the mental within philosophy of mind and psychology certainly seems to have created hard times for ethics. Eliminative materialists like Stich (1983) attack the very foundation on which moral theories are based. Since moral theories assume a certain amount of intentionality as a building block for their legislation of rights and obligations, any positions that could demonstrate in some form that such an assumption is unwarranted, in that beliefs, desires and mental states in general cannot be shown to exist, would seem to spell death for the ethical realm. If moral theories require realism about cognitive elements and their states yet are unable to present us with the evidence that will support this requirement, then they must either give up this requirement, and accept the view that moral agents and subjects no longer have any sure footing with regard to their claims concerning moral behavior toward themselves and others, or recognize some other way on which to ground their views. Does it have to be the case, for instance, that consciousness and sentience are the only conditions on which moral status can be ascribed to beings? Or can we refer to some other condition or set of conditions? Can we perhaps expand our concept of morality to include animals yet without

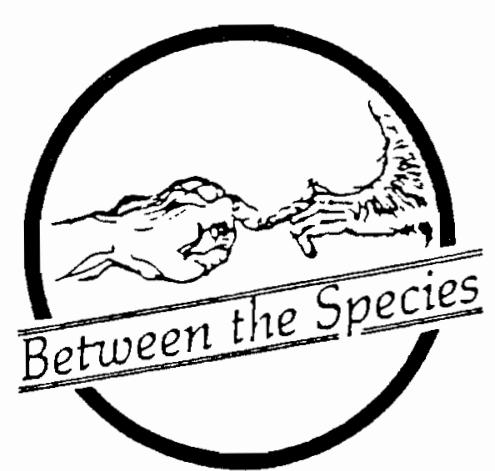

necessarily raising the problems associated with attributions of intentionality? The general focus of this paper, then, concerns my interest in the conditions that make moral judgments about animals true. Hence, I am concerned with moral epistemology, not axiology.

In Part I, I present a cursory analysis of Stich's view concerning ascriptions of beliefs to humans as well as to animals. In Part II, I analyze Regan's arguments for why certain animals ought to be regarded as moral subjects as well as his response to Stich's position. My intention behind presenting Regan's position is twofold: (1) to show that Stich's position creates some difficulty for Regan's ultimate goal of ascribing rights to animals and (2) to point out that the comparison of animal to human belief structures is not an effective way to ground what possible claims they may have against us. I conclude on a somewhat Heideggarian note in Part III. I argue that animals and nature itself may be deserving of some moral recognition just by virtue of the fact that they afford us possibilities with respect to what we can and do become. "Value," in a certain sense, is to be found external to ourselves.

\section{Part I}

In their effort to respond to reductionists who contend that beliefs comrespond to certain neurological states, eliminativists want to discard the intentional

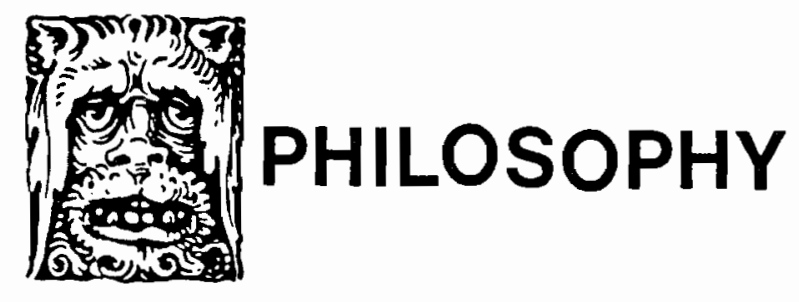


idioms employed by folk psychological theories. Their main purpose for doing so is that such mentalistic vocabulary does not refer to anything. They eventually hope to employ a new language, one which would better explain human behavior. At the other end of the spectrum, instrumentalists, proceeding on a more extensive concept of "belief," contend that we can still adequately explain behavior with our folk psychological concepts, i.e., that "beliefs," "desires," "expectations" and the like are helpful heuristic devices for the prediction of behavior. The instrumentalist's concept of belief ascriptions is not limited to the description of neural events but also involves reference to our environment. Whether or not we really do have beliefs, however, is not their primary concern. What's important is that our predictions work. Realists, like Fodor, take the fact that we have managed for thousands of years with these predictions as a certain amount of evidence supporting their view that beliefs do exist. But, of course, one can't just isolate this fact as adequate evidence that beliefs do in fact exist, since to do so would amount to nothing more than an ad populum. Clearly, more needs to be said on the subject, and one must recognize that eliminativists are waiting in the wings to wam us that we may not only be overly optimistic about the accuracy of these predictions; we may also be overrating our very ability to predict behavior.

Although generally referred to as an eliminativist, Stephen Stich appears to occupy a midway position between the eliminativist and the instrumentalist. Stich advocates a syntactic theory of mind which holds that while there is no type-type theory with regard to one's mental states and physical states, i.e., that one is not reducible to the other, there seems to be something akin to a type-token system where certain amounts of "mentalese" appear to "map onto" certain amounts of physical states. My belief that "I have a headache," for example, means more than the experience of a particular chemical disbalance; in addition, it refers to my awareness that having such an experience is one to be avoided. So Stich, in this sense, shares the wider sense of belief that the instrumentalist employs. However, acceptance of this view in no way cornmits Stich to the position that there really are beliefs, desires, etc. Stich, of course, denies any such inference, and it is in this sense that he is considered an eliminativist. Although he is sympathetic to the plight of the folk psychologist here, he remains open to the possibility of finding some new medium with which to interpret behavior. Hence, he adopts what is referred to as the "Quinean double- standard:"1 i.e., he takes the position that beliefs don't exist in light of folk ps ychology's inadequate evidence for their existence, yet he also takes the position that allowing a total dispensation of our intentional idioms would leave us, to borrow a phrase from Wittgenstein, "unable to go on" as we have been. So, Stich is content, at least presently, with saying that there are events that we refer to as "the belief that p" but that such expressions don't refer to any one type of event.

Given that, Stich goes on to give an account of what he believes warrants our intuitions regarding belief ascriptions. When we attribute "the belief that p" to another, Stich points out that there exists an assumption on our part that this other individual is like us in that he will arrive at the same conclusion(s) given the same context. What's going on here is not so much an assumption of similarity with respect to the content of another's state but rather an assumption of similarity with respect to the behavior expected. Any description given of individuals as having the same belief will reflect the interests and expectations of the attributor, and nothing more than that, and, of course, this supposition also holds for ascriptions of mental states to animals as well. Stich lays out three different criteria for determining whether or not someone can be said to have beliefs similar to others in their group: the first criteria is in terms of functional or causal-pattern similarity; the second condition emphasizes referential similarity; and the third factor is ideological similarity. Stich's purpose behind listing the above factors is to show how some contexts will highlight reference, while others will emphasize the other factors. Which one gets emphasized depends, of course, on the concerns of the one ascribing the belief.

Let me explain each of these factors briefly. In order to have two beliefs count as causal-pattern similar, there would have to be some demonstration that the perceptual and inferential abilities were alike enough to warrant them both having "the belief that p," i.e., that the individuals would have to act similarly given the same situation or, to put it in another way, that these individuals were disposed to behave in sinilar ways. Given, for example, that the brain functional capacities of advanced Alzheimer patients are so impaired, and as a result many of the statements they utter are inappropriate to the contexts that they're stated in, we would be inclined to say that their beliefs in those instances are unlike ours and that they are in a different type of mental state. Referential similarity and 
ideological similarity seem to assume a certain amount of functional similarity, but it's not clear that that would have to be the case. Leaving that point aside, two individuals can be said to exhibit referential similarity if the object of their beliefs is the same. If what I'm referring to is not what you're referring to when we utter the same word or phrase, then we can't be said to share the same belief. Ideological similarity implies a shared network of beliefs. Two people are counted as ideologically similar if they can draw certain (basic) inferences from the statements that are uttered by themselves and/or other speakers. If, for instance, I utter the statement "Tom is an astronaut" yet can give no explanation of who Tom is nor any explanation concerning what an astronaut is, you would be justified in claiming that, ideologically, I am dissimilar to you. I am, in any event, using words that I don't understand.

Now, this set-up does permit us to say when it is appropriate to ascribe beliefs and other propositional attitudes to an individual, but how does it fare with respect to animals? Stich believes that, in general, animals

are causal-pattern dissimilar, since neither their perception nor their inferential capacities work quite the way ours do. And they are ideologically dissimilar, since their doxastic network differs markedly from our own. Since they have no language, reference similarity is out of the question, though the causal history component of reference similarity may have an analogue in the causal history of animal concepts...(These) dissimilarities lead us to expect that we will have conflicting intuitions about the appropriateness of using everyday English content sentences to characterize the cognitive states of animals. ${ }^{2}$

Indeed, it seems that in many situations it would be difficult to specify the contents of animal beliefs and other propositional attitudes. This seems true especially with regard to the behavior of certain animals like frogs, for example, and in such cases one really wouldn't need to revert to anything more than Dennett's design level in an effort to understand the frog's "psychology." ${ }^{3}$ But can we say the same for Fido? The dog is physiologically more complex than the frog (it is more like us in that regard), and its behavior exhibits that complexity. Unlike the frog, it appears to have expectations (its movement toward the front door when its Master is due to arrive home), desires and goals (its jumping up and down for its ball and its running in order to get the ball). But is it the case that Fido has such beliefs, desires, etc.? Stich is willing to allow the ascription of certain beliefs and desires to animals if they exhibit similar patterns of behavior. In like circumstances, if humans can be said to have beliefs, then so can animals. ${ }^{4}$ The interesting issue here, though, is whether animals do exhibit similar patterns of behavior and whether it is evident enough of the time for us to warrant some assumption of similarity. In any event, whatever Stich decided, he would not ascribe full-fledged similarity. He really believes animals to be too unlike us for that.

In what follows, I look at Regan's arguments for why certain animals can be said to be enough like us to justify ascriptions not only of beliefs and other propositional attitudes to them, but also ascriptions of value to them.

\section{Part II}

In The Case for Animal Rights, Tom Regan presents his Cumulative Argument ${ }^{5}$ in order to show that consistency requires an attribution of consciousness and sentience to (certain) animals just by virtue of the fact that humans, who have evolved from such animals, are shown and said to have such characteristics. The animals he refers to here are mammalian animals, one year and older, and he sets out to prove that such animals satisfy his Subject-of-a-Life Criterion and, hence, can be said to have inherent value based on that satisfaction. A Subject-of-a-Life is described as one who has

beliefs and desires; perception, memory, and a sense of the future, including their own future; an emotional life together with feelings of pleasure and pain; preference- and welfareinterests; the ability to initiate action in pursuit of their desires and goals; a psychophysical identity over time; and an individual welfare in the sense that their experiental life fares well or ill for them, logically independently of their utility for others and logically independently of their being the object of anyone else's interests. ${ }^{6}$

Regan points out that animals such as Fido fulfill this description, that they do have certain preference-beliefs and will seek to satisfy such desires. This, Regan 
argues, is evident when we observe Fido digging up a certain spot in order to retrieve his bone. Can this behavior be explained solely at the design level? No more than ours can, given its complexity. This type of action indicates that what is occurring is more than just a mere disposition to behave a certain way. Some second-order intentionality is apparent in its behavior. Fido, in certain contexts, does seem to be "happy," "eager," "ashamed," etc. But, as Regan warns us, in order to justify these ascriptions, we cannot view the animal's behavior atomistically, e.g., just see Fido's tail wagging and infer from that that Fido is "happy." We need to justify those ascriptions on a holistic basis, i.e., recognize the relation obtaining between the context and Fido's behavior. ${ }^{7}$ If we follow the latter method, we will be able to offer some assessment (an adequate one for Regan) of Fido's actions and, hence, be able to predict certain patterns of behavior. And this, of course, resembles what we do in our assessment of human behavior to a certain extent.

Regan, however, wants to go a step beyond what Stich and others would be willing to do at this point. He claims that animals like Fido also possess certain (albeit partial) concepts of things in the world. Fido, for instance, has his concept of a bone, i.e., that it is something to bury, something to chew on, something that will satisfy a certain craving, and the like. ${ }^{8}$ Stich, however, draws the line at this point: if Fido really does have such a concept, then why doesn't he treat other things that are bones as bones? ${ }^{9}$ What Stich is looking for here is some evidence that Fido views bones qua bones. Stich elsewhere ${ }^{10}$ raises the following similar point:

does Fido really believe it is a squirrel up in the oak tree? Are there not indefinitely inany logically possible creatures which are not squirrels but which Fido would treat indistinguishably from the way he treats real squirrels? Indeed, does he believe, or even care, that the thing up the tree is an animal? Would it not be quite the same to Fido if he had been chasing some bit of squirrel-shaped and squirrelsmelling machinery, like the mechanical rabbits at dog-racing tracks?

What Stich obviously wants to einphasize here is that Fido is ideologically dissimilar to us, that Fido, for instance, does not possess the concepts of living and non-living which are part of our concept of animal. This seems true to a certain extent, but this point by itself does not suffice as an adequate refutation of Regan's contention that Fido has some concepts. After all, what are the essential features in recognizing that the object is squirrel? Aren't the shape and the smell here the outstanding and necessary features to notice?

However, although I am sympathetic to Regan's claim that Fido does have some concept, even if it is a limited one, of a bone or a squirrel, there still needs to be more said on the nature of concepts. What would constitute the identity conditions for a concept? For instance, how extensive must the set of beliefs be in order for one to say that they have such a concept? Is it enough, for example, to say that I have the concept of a bone if I only have the beliefs that bones have a certain shape and density? At what point do I qualify as having the concept? If I am fooled, or am unable to pick out the referent in this one case, does that entail that I don't have some understanding of what a bone is? It is interesting to note at this point in the discussion that if another human being surprises us by her behavior in a certain case, which is just to say that she hasn't met our expectations in that situation, we usually tend to adopt a principle of charity toward her. We attempt to reconstruct some rationality to her situation. For example, the secretary in our office tells me that she is so hot and would love to have an ice cream cone. She then goes on to count her change, realizing that she has enough money to buy one. And off she goes to the University Union where they sell ice cream cones. So guess what I believe she'll come back with? But she doesn't come back with an ice cream cone; she returns instead with a sandwich. Do I now see her as irrational? No. I say to myself that "she must have had some reason for deciding the way she did." I give her the benefit of the doubt. But, in the case of animals, even our faithful Fido, we rarely apply a principle of charity in their situations.

At most what can be said at this point is that the extension of Fido's "concepts" of bone and squirrel are different from ours. And so, by Stich's standards, this would indicate a certain amount, at least, of referential dissimilarity. Yet, the important question here is: even if there is a lot of ideological and referential dissimilarity between animals and us, does it follow that we can do what we want to them? Is there some other way to ground the view that animals deserve a certain amount of ethical treatment other than referring to views 
concerning intentionality and its related issues? How do we convince others that the fight here is worth it? I now turn to Part III.

\section{Part III}

Keep in mind that Regan's purpose behind his arguments is to make a "case for animal rights." He ascribes rights to animals on the basis that they have inherent value, that they satisfy his Subject-of-a-Life Criterion. ${ }^{11}$ Yet, note what is actually going on here: in his effort to abandon species-chauvinism, he has, in fact, been species-chauvinistic. The human belief-structure is the paradigm with which he compares other animals. The closer they are to being like us, the more we are willing to ascribe them some value. It seems to me, though, that the important issue here is not whether animals can be said to have concepts or are ideologically similar or dissimilar to us. In fact, concentrating solely on those aspects seems to miss the mark of a moral theory which should be to construct sensible and acceptable, if not ideal, norms for behavior. And, it's not clear to me why we necessarily have to posit intentionality as the deciding factor in questions concerning what is to count as valuable and, hence, deserving of moral respect.

In general, moral theorists have consistently viewed the human animal as the most valuable one, as the one whose interests and rights can override the rights (if there be any) of any other being in the world. In fact, many theorists believe that humans deserve greater moral consideration by virtue of the fact that they are autonomous beings and capable of doing more things than the "lower" animals. But is desert warranted here? Holding this position amounts to no 1nore than viewing our position in the evolutionary scale as analogous to some achievement on our part, that it's somewhat of an accomplishment that we "managed" to get to the top of the process, and because of that, we've earned a certain amount of consideration. Yet this is not the case: we are just members of a species that evolved, and with that process came a greater adaptability to the environment. So as a species we ended up with an advanced belief structure. Yet having a greater potential to manipulate one's environment is not something we earned.

We should also at this time keep in mind that if it turns out that eliminativism is true, we are not in a better position than the animals here. If we have a problem grounding our own intentionality, how will we ascribe moral worth to ourselves? If it turns out that beliefs and desires are fictions, what will become of our status as moral agents? Gregory Sheridan raises this concern in the following way:

The concept of a moral agent may be largely a prescriptive or evaluative one. It will depend on details of the version of compatibilism socially practiced or defended. The concept of a moral subject, on the other hand, is a descriptive or natural one. ${ }^{12}$

Keeping in mind that the requirements for moral subjectivity are just consciousness and sentience, Sheridan completes his point by stating

Chuck the concept of a moral subject, our belief that ourselves and others deserve moral consideration,... and we have nothing. Moral reasoning loses its point altogether. ${ }^{13}$

Clearly, we want to save our notion of a moral subject, yet without necessarily talking about beliefs per se or any other related intentionality issue. I propose that we move from a purely Kantian view to a more Heideggarian one. This is to essentially view value as external to ourselves, not as originating with ourselves. Taking this position, of course, requires that we lose some of our self-importance, that we view ourselves as part of the world, as members of a species among other species. It is to adopt a holistic attitude toward nature and, hence, recognize that Nature itself is a necessary condition for our existence. The existence of things in nature has afforded us not only life but also possibility. We are what we are because of IT. IT allows us to flourish; IT lets us $b e$. And because of that, we need to adopt an attitude of graciousness, i.e., realize that we have been graced with existence and possibility. IT gives us this, and for that we need to realize ITs value. An attitude of graciousness, then, requires an attitude of respect, not harm. And this attitude of respect is not just limited to animals; it should also open the door to the environment itself.

Eliminativism, then, doesn't have to pose a threat to us. But this will entail changing our view of ourselves as all-important by virtue of our rationality to one which realizes that, at base, we are one species among many and that these others give us (to a great extent) our being. 


\section{Notes}

${ }^{1}$ Daniel Dennett, The Intentional Stance (Cambridge: The MIT Press. 1987), p. 342.

${ }^{2}$ Stephen Stich, From Folk Psychology To Cognitive Science: The Case Against Belief (Cambridge: The MIT Press. 1983), p. 104.

${ }^{3}$ Dennett, op. cit., p. 109.

${ }^{4}$ Stich, op. cit., p. 106.

${ }^{5}$ Tom Regan, The Case For Animal Rights (Berkeley: University of California Press. 1983), pp. 25-30.

${ }^{6}$ Ibid., p. 243.

${ }^{7}$ Ibid., p. 68 .

${ }^{8}$ Ibid., pp. 58-59.

${ }^{9}$ Ibid., p. 50 .

${ }^{10}$ Stich, op. cit., pp. 104-105.

${ }^{11}$ It is interesting to note, however, that although Regan shows these animals to have inherent value and awards them rights based on this inherent value, such rights get overridden in the event of a conflict with a human's rights.

${ }^{12}$ Gregory Sheridan, "Can There Be Moral Subjects in a Physicalistic Universe?," Philosophy and Phenomenological Research 43 (1983): 447.

${ }^{13}$ Ibid., p. 446.

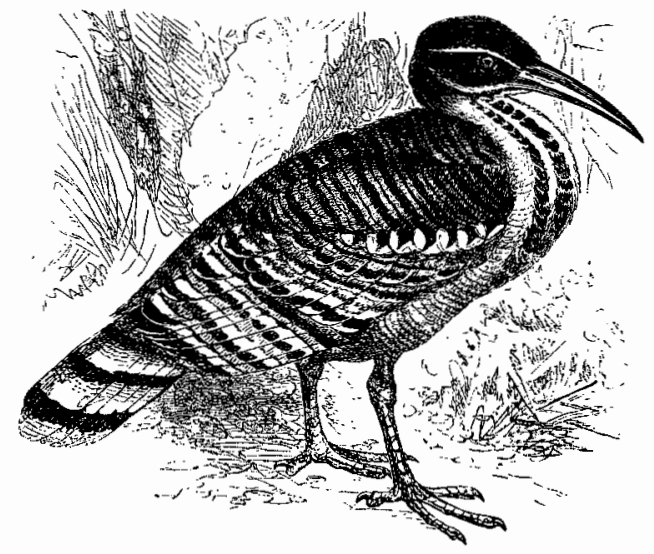

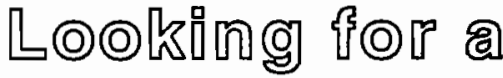

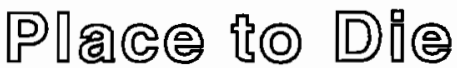

He arrived one day

And claimed a corner of the yard. The whirling dervish tomcat bully Tried his usual tricks

But he just wearily hissed

And stayed

Curled up tight

On his bed of leaves

For over a day.

He walked right into my heart This sad old battered old cat. He had a certain dignity Hissing while arching his chin To be rubbed.

Wanting comfort

Yet not believing in it.

He wasn't pretty,

Aged and clumsy and tired

Big old jowls

And black and white splotched fur,

Which only once in a while

He washed after eating.

He took up residence in the old doghouse Empty since my dog died

But full of warm clean straw.

I had to tempt him out to eat.

I knew what he wanted.

Once before I had found a cat

Looking for a place to die

And I had tempted her

To choose life.

And so, once again

I will weigh the balance

And for better or for worse

Persuade this old traveller

To live

And to find reason to live.

Mary de La Valette 